\title{
GRANDE ESTRATÉGIA: POLÍTICA EXTERNA E DEFESA EM UM MUNDO EM TRANSFORMAÇÃO'
}

\section{Celso Amorim²}

No dia 2 de janeiro de 20I4, um atentado a bomba em Beirute feriu 60 pessoas e tirou a vida de pelo menos cinco, entre elas a brasileira Malak Zahwe. A jovem Malak, nascida em Foz do Iguaçu, morava com a família no Líbano, e estava fazendo compras com sua madrasta quando a explosão ocorreu. Uma grande comunidade libanesa vive entre nós e um número crescente de brasileiros reside no Líbano. Temos uma ligação próxima e direta com aquele país. Como nos recordou o bárbaro atentado de janeiro de 20I4, essa ligação é, acima de tudo, uma ligação humana.

Situações trágicas como essa reforçam a compreensão de que somos parte da sociedade global. A indiferença frente aos desafios com que nos deparamos no estrangeiro não é mais cabível. Atitudes isolacionistas do tipo "não devemos nos meter em assuntos que não são nossos" revelam não apenas insensibilidade, mas também alta dose de irrealismo e incompreensão. Um dos efeitos da tão propalada globalização é que "todos os assuntos são nossos".

Temos um interesse claro na paz mundial, e devemos contribuir para preservá-la. Foi o que o Brasil tentou fazer, com êxito em alguns casos, e lançando sementes que germinariam mais tarde em outros. Atraímos Cuba para o Grupo do Rio e para a CELAC. Hoje aquele país convive pacificamente com todas as nações das Américas. Juntamente com a Turquia, empenhamo-nos em negociações com o Irã sobre seu programa nuclear que, quando menos,

I Texto baseado parcialmente em palestra proferida na Escola de Guerra Naval em I4 de maio de 2015 .

2 Diplomata brasileiro e ex-Ministro da Defesa. Ao longo de sua carreira, ocupou o cargo de Ministro das Relações Exteriores do Brasil. Pesquisador do Núcleo Brasileiro de Estratégia e Relações Internacionais (NERINT). 
demonstraram que havia campo para buscar soluções por meio do diálogo para a espinhosa questão do programa nuclear iraniano. Hoje, nos dois casos, felicitamos os avanços realizados pela maior potência do mundo.

Em outra ocasião, afirmei que o Brasil não deveria se contentar em ser um país pacífico, mas deveria buscar ser um país "provedor de paz". Para tanto, o Brasil deve adotar uma grande estratégia que conjugue política externa e política de defesa. Naturalmente, a diplomacia é a primeira linha de defesa dos nossos interesses. E o diálogo dever ser seu principal instrumento. Mas em um mundo em que o conflito está longe de ser extinto e as grandes potências frequentemente recorrem a ações unilaterais, a diplomacia deve ter o respaldo permanente da política de defesa.

Muito se fala do poder brando, desde que Joseph Nye, professor de Harvard e ex-secretário Assistente de Defesa, cunhou o termo. Trata-se de conceito inovador, que se aplica a muitas características do Brasil e seu povo, sua cultura e sua tradição de paz. Mas nenhum país se afirma no mundo somente pela atração de sua cultura e de seus hábitos. E há situações, como a que vivemos durante a II Guerra Mundial, em que o poder brando por si só não é suficiente para prevenir agressões ou incursões que afetem nossa soberania. Por isso, ao mesmo tempo em que cultivamos e exercitamos o nosso poder brando, devemos tratar de robustecê-lo. Nosso poder brando (soft power), expresso na capacidade de cooperar de forma mutuamente benéfica com outros países, será reforçado por nosso poder robusto (hard power), capaz de dissuadir ameaças e de tornar a colaboração com nossos vizinhos e parceiros, em matéria de defesa (por exemplo na proteção de recursos naturais) uma realidade.

A até aqui bem sucedida experiência no Haiti, em que contribuímos para restaurar a ordem naquele país, devolvendo ao povo haitiano a capacidade de decidir sobre o seu destino, é um exemplo de combinação de poder brando e poder robusto em uma situação em que não se tratava de uma ameaça imediata ao nosso país. No Haiti existia o risco, muito real, de que uma nação irmã, com a qual temos muitas afinidades - e que, afinal, não está tão distante de nós - caísse sob o domínio de bandos armados, uma combinação perversa de ex-militares golpistas e traficantes. Foi a propósito do Haiti que cunhamos (ou tomamos emprestado da União Africana, até hoje não estou certo) o conceito de "não indiferença".

A presença de uma fragata da Marinha do Brasil na componente marítima da Força Interina das Nações Unidas no Líbano, a Unifil, é outra ilustração de como o emprego de instrumentos militares pode reforçar a ação diplomática na busca da paz. Apesar das grandes dificuldades que o Líbano enfrenta, temos a certeza de estarmos cumprindo nossa responsabilida- 
de para com essa nação amiga. Além disso, reforçamos com nossa presença militar, os trunfos para uma eventual atuação politico-diplomática, quando as condições da região permitirem. Há uma ou duas décadas, a participação de um navio de guerra brasileiro em operações no Mar Mediterrâneo, um dos mais tradicionais tabuleiros da geopolítica mundial, seria vista como altamente improvável. Hoje, mesmo os críticos do envolvimento brasileiro em questões aparentemente distantes, como as do Oriente Médio, não parecem duvidar da importância de nossa contribuição à Unifil. Essa evolução não deixou de guardar relação com os impactos muito diretos da guerra de 2006 entre Israel e Líbano, na qual sete brasileiros morreram e três mil compatriotas foram evacuados por via aérea para o Brasil, em uma operação coordenada pelo MRE com o decisivo apoio de nossa Força Aérea. Eu estive em Beirute, no dia seguinte ao cessar fogo, e pude ver, com os meus olhos, o testemunho eloquente da proximidade entre os dois povos: camisetas da seleção brasileira e bandeiras do Brasil em meio aos escombros e destruição causada pelos bombardeios israelenses.

Nossa participação no Líbano, bem como nossa atuação diplomática em situações como as que levaram à “Declaração de Teerã” sobre o programa nuclear iraniano, e também o convite para participarmos na Conferência de Annapolis sobre o conflito Israel-Palestina ${ }^{3}$ sublinham a importância de refletirmos sobre nossos desafios e de definirmos nossos interesses. Temos de pensar sobre nosso papel no mundo sem complexos e com autonomia. A concepção de uma grande estratégia autenticamente brasileira - envolvendo política externa e política de defesa - resultará de um amplo diálogo público acerca de nossos desafios e prioridades, que envolve os meios políticos, diplomáticos e militares, com a participação da academia, da mídia, dos setores produtivos (empresários e trabalhadores) e da sociedade de modo geral. A publicação em 20I3 do Livro Branco da Defesa e de edições revistas da Política Nacional de Defesa e da Estratégia Nacional de Defesa deve ser vista como parte desse diálogo.

Muito já se escreveu sobre a natureza fluida da realidade internacional. Nos últimos anos do século XX, com o fim da guerra fria, passamos da bipolaridade para uma espécie de "unipolaridade consentida". Posteriormente, já no novo milênio, o mundo evoluiu para uma estrutura mista, que conserva traços da unipolaridade, mas que, em certos aspectos, se aproxima de um mundo multipolar. Ao mesmo tempo, vemos se desenhar, no horizonte, uma potencial nova bipolaridade, com a China assumindo, mutatis mutandi, o papel da antiga União Soviética, sem o fervor ideológico.

3 Trato desses dois temas em duas das narrativas do meu mais recente livro Teerã, Ramalá e Doha: memórias da política externa ativa e altiva (Benvirá, 20I5). 
Vivemos em um tempo de mudanças rápidas, profundas, mas marcadas por ambivalências. A emergência de novos atores e das chamadas "ameaças assimétricas”, frequentemente mencionada por estudiosos de defesa e de relações internacionais, não eliminou os antigos agentes na ordem mundial. E o conflito entre Estados não desapareceu de todo do horizonte. Mesmo em tempos de globalização econômica, os Estados nacionais guardam sua importância e a soberania segue sendo um princípio condutor. A "comunidade internacional" foi frequentemente invocada para justificar ações que correspondiam ao interesse de uma ou mais de uma grande potência. A "responsabilidade de proteger", consagrada em resoluções da ONU, foi invocada em situações em que o verdadeiro objetivo era a "mudança de regime" e não, como alegado, a "proteção de populações civis". O multilateralismo não superou a defesa de posições nacionais.

$\mathrm{Na}$ esteira da crise financeira global de 2008 , tomou corpo nos Estados Unidos um amplo debate acerca do suposto declínio de sua posição relativa no mundo. Eu mesmo, quando estive em Harvard por um mês, em uma fellowship da famosa Kennedy School of Government, depois de ter deixado a Pasta das Relações Exteriores, há quatro anos, pude assistir a várias discussões e debates em que o declínio relativo (ou não) dos Estados Unidos era um tema central para os próprios acadêmicos norte-americanos. Voltei àquela instituição após minha saída do Ministério da Defesa, em 2015, e verifiquei que o eixo da discussão mudou. Hoje, mais que a multipolaridade, é a ascensão da China, sua influência econômica e sobretudo sua estratégia de projeção marítima que despertam interesse e apreensão. A lógica do interesse nacional, mais do que qualquer outra, preside a definição de posições. É nesse quadro que se deve entender o estímulo a que o Japão retome um papel militar e estratégico, que havia sido abandonado após a II Guerra Mundial.

Em um mundo em que as ideologias perderam peso na definição das políticas nacionais, as coalizões de Estado, mais do que nunca, espelham uma geometria variável. Apesar dos esforços de Washington, os governos das grandes economias europeias não se furtaram a participar do Banco Asiático, liderado por Beijing. O antigo grupo das sete grandes economias industrializadas, o G7, evoluiu rumo ao G8, com a incorporação temporária da Rússia (mais por seu status nuclear do que por seu peso econômico), e daí ao G2o, que incluiu as economias emergentes e que foi definido pelo presidente dos Estados Unidos como tendo o principal papel (primary role) em temas econômicos e financeiros. O ressurgimento recente do G-7 não muda este panorama. E, na realidade, é um fato muito menos relevante do que a crescente coordenação entre os membros dos BRICS. Alguns autores passaram a achar que, com a gradual dissipação do excedente de poder da superpotência, esta- 
riam dadas as condições para um chamado "G-Zero", no qual nem os Estados Unidos poderiam liderar, nem os demais países estariam dispostos a seguir. Fareed Zakaria, entre outros, chamou a atenção para o que ele definiu como the rise of the rest ${ }^{4}$.

Quaisquer que sejam esses "Gs", temos hoje uma realidade complexa, que não se presta a modelos ditados pelo "pensamento único". Há amplo consenso de que estaria em curso uma desconcentração do poder nos campos político, econômico e cultural e, mesmo (talvez em menor grau), nos campos científico e tecnológico. A multipolaridade, mesmo que imperfeita, tem despertando esperanças de um mundo mais equilibrado e livre de hegemonias. Entretanto, no campo militar a unipolaridade continua, em larga medida, a prevalecer. Basta lembrar que os gastos com defesa nos Estados Unidos superam a soma das despesas militares de todos os demais países. Os avanços desse país em áreas como a cibernética não têm equivalentes em outras potências.

Apesar dessa superioridade, fatores psicológicos e sociais variados, sobretudo o crescimento da aversão às mortes de compatriotas, graficamente transmitidas pelos meios modernos de comunicação, reduzem as margens para a projeção do poder militar em outras regiões. Se a televisão contribuiu de alguma forma, com suas imagens cheias de tragédia sobre as vítimas do napalm, para apressar o fim da guerra do Vietnã, pode-se imaginar o que fariam as redes sociais, o twitter, etc. em uma situação similar nos dias de hoje. Daí a busca incessante de meios de destruição "sem risco" ou de baixíssimo risco como os drones e as ameaças de guerra cibernética. Mesmo formas menos avançadas de ataques com baixo risco foram aplicadas, por exemplo, nas operações militares contra a Sérvia, no Kosovo, onde os bombardeios aéreos eram realizados a grandes altitudes, o que impedia o discernimento preciso dos alvos. Tanto em um caso como em outro, os efeitos colaterais sobre populações civis são consideravelmente aumentados.

A exceção a essa aversão à exposição ao risco ocorreu apenas - e com as qualificações acima - em situações em que a segurança do próprio povo norte-americano foi percebida como diretamente ameaçada, como ocorreu no ir de Setembro. Apesar de toda a repulsa causada pelo chamado "estado islâmico", o número de sortidas aéreas contra os militantes do ISIS ou ISIL é infinitamente menor do que o que se verificou na segunda guerra do Golfo, que resultou na derrubada do regime de Saddam Hussein.

A suposição comumente compartilhada é a de que, em um "mundo pós-hegemônico”, as instituições internacionais criadas ao final da Segunda

4 Zakaria, Fareed. The post-American world and the rise of the rest. (Penguin Books, 2009). 
Guerra seriam mantidas. Com a provável superação dos Estados Unidos pela China como a maior economia do mundo nas próximas décadas, seria conveniente para todo o mundo e para os próprios Estados Unidos que Washington abandonasse a lógica do excepcionalismo e aderisse, de forma mais estrita, às normas de instituições multilaterais. As corajosas iniciativas do Governo Obama em relação ao Irã e a Cuba permitem algum otimismo, em que pese às resistências de setores mais conservadores norte-americanos.

Isso também traria benefícios para os demais países, assegurando-se certo grau de estabilidade às relações internacionais. Esses benefícios, entretanto, só serão plenos, no caso das nações em desenvolvimento, caso o compromisso com normas internacionais se faça acompanhar de reformas efetivas do processo decisório dessas instituições, a começar pelo Conselho de Segurança da ONU. Mas em relação a esse tema, a oposição maior parece provir não tanto da ainda maior potência - que mantém uma posição ambivalente sobre a ampliação - mas de outros quadrantes, inclusive da China, nossa sócia nos BRICS, o que mais uma vez sublinha a complexidade das relações entre Estados no mundo contemporâneo.

Em artigo recente, Kofi Annan e Gro Harlem Brundtlands fazem uma proposta de compromisso interessante: mandatos de longa duração, com os membros de longo mandato reelegíveis indefinidamente. Mas mesmo essa solução intermediária parece de difícil adoção no curto e médio prazo, uma vez que ela implica reforma da Carta de São Francisco, o que requer a ratificação das eventuais emendas por 2/3 dos Estados membros, inclusive os chamados P5. Um G-20 que passasse a se ocupar também de temas relativos à paz e a segurança internacionais - sem prejuízo da retenção pelo CSNU do poder último de decisão - parece oferecer a melhor esperança de um maior grau de descentralização da ordem internacional, injetando "ar fresco" nas discussões sobre tais temas.

Em relação à situação do Oriente Médio, as principais potências pareceram, em certo momento, entender a importância de uma participação mais ampla de países de várias regiões, inclusive nações em desenvolvimento. O convite de Washington a que Brasil, Índia e África do Sul participassem da Conferência de Annapolis, em dezembro de 2007, ilustra esse tipo de entendimento. Evidentemente, arranjos informais como o do G-20 não podem substituir a necessidade de um Conselho de Segurança reformado, que deve continuar a ser um objetivo estratégico da política externa brasileira, com reflexos na política de defesa. A reforma do CSNU é, necessariamente, parte integrante da "Grande Estratégia" do Brasil.

5 Disponível em: http://www.nytimes.com/2015/02/o7/opinion/kofi-annan-gro-harlembruntland-four-ideas-for-a-stronger-un.html?_r=o 
Os autores que admitem a retração (absoluta ou relativa) da hegemonia norte-americana apontam as contradições que ela envolve. O envolvimento político e militar da superpotência em múltiplos conflitos e crises ao redor do globo, consequência da lógica de hegemonia global que resultou do fim da Guerra Fria, drenaria recursos indispensáveis a investimentos em outras áreas como o meio ambiente, a saúde ou a educação. Um menor envolvimento implicaria, por sua vez, revisão dos compromissos com vários aliados e, de forma geral, o desengajamento de uma série de teatros de operação. Dependendo do ponto de vista, uma evolução desse tipo pode ser vista como positiva ou negativa, mas teria implicações importantes para o ordenamento internacional.

Um ponto comum a essas teses, todas elas publicadas no âmbito do debate norte-americano, é o reconhecimento de uma tendência de redução, discreta, mas perceptível, de algumas das assimetrias que separam a superpotência dos demais Estados. O exame de algumas dessas teses "declinistas" reforçaria a leitura de que a redistribuição do poder mundial é fenômeno de alcance ainda imprevisível. Por ora, não é possível dizer se o novo ordenamento pós-unipolar se consolidará como multipolaridade, isto é, uma distribuição do poder mundial entre um certo número de Estados - ou agrupamentos de Estados -, em relativo equilíbrio, ou se, como aventado acima, tomará a direção de uma nova bipolaridade, desta vez entre os Estados Unidos e a China.

Olhando o mundo do nosso ângulo e, com o indispensável realismo, parece certo afirmar que ainda persistirá por algum tempo, senão uma realidade unipolar, ao menos uma mentalidade unipolar. $\mathrm{O}$ aspecto mais preocupante dessa mentalidade é que ela não é puramente descritiva ou analítica, mas traz embutido um elemento prescritivo do tipo "temos que aceitar a realidade e nos adaptar a ela”. Em outras palavras: caberia ao Brasil, segundo essa visão acanhada, continuar a desempenhar um papel secundário no cenário global, submetendo-se à estratégia da potência dominante e buscando, no máximo, extrair vantagens de uma associação subalterna.

Igualmente perigosa é a equiparação entre hegemonia e estabilidade. Na visão "hegemonista", que predominou no imediato "pós-guerra fria”, a estabilidade seria garantida por uma certa "dominação benigna”. Como a década passada demonstrou, a tese de que a hegemonia gera estabilidade é falaciosa. A invasão do Iraque e a subsequente desestabilização da precária ordem do Oriente Médio, em sentido contrário aos interesses da própria superpotência, inclusive com a expansão do terrorismo, são testemunho eloquente de que a hegemonia gera insegurança, não estabilidade.

Tucídides, em sua magistral narrativa da guerra entre os povos helênicos, já compreendia perfeitamente esse ponto. Logo no começo da Histó- 
ria da Guerra do Peloponeso, o historiador ateniense explica que a origem do conflito foi o alarme gerado em Esparta pelo excessivo acúmulo de poder em Atenas. Em outra parte da obra, Tucídides faz um esclarecimento de importância transcendente sobre o assunto, e válido até os dias de hoje: "Não culpo aqueles que desejam dominar, mas sim aqueles que se submetem muito rapidamente. É tão próprio da natureza do homem dominar aqueles que se submetem a ele, quanto o é resistir àqueles que o atacam" (IV, 6I). Essas palavras se aplicam com muita propriedade quando se busca explicar a oposição de vários Estados ao ataque ao Iraque em 2003. Tal oposição refletiu também preocupação com a integridade do sistema normativo da Carta das Nações Unidas, o qual proscreve o uso da força sem a autorização prévia e explícita do Conselho de Segurança (exceto em caso de legítima defesa, conceito que deve sempre ser interpretado de forma cautelosa e restritiva $)^{6}$.

A perspectiva histórica lança uma luz adicional à razão por que o Brasil passou a trabalhar incansavelmente, a partir do início da década passada, no sentido de estimular os incipientes elementos de multipolaridade do mundo contemporâneo. Não só do ângulo dos princípios, mas até do pragmatismo, o unilateralismo, estimulado pela hegemonia, trouxe consequências contrárias às desejadas. O objetivo da multipolaridade foi buscado pelo Brasil em diferentes frentes, como a alta prioridade atribuída à integração da América do Sul; o pleito pela democratização das instâncias decisórias das Nações Unidas; a busca de maior justiça nas negociações comerciais, na Organização Mundial do Comércio; e a articulação com novos parceiros do mundo em desenvolvimento, como os membros do IBAS e dos BRICS, mas também com países árabes e africanos. Desnecessário dizer que motivações econômicas, culturais e humanas também estiveram presentes, em graus diversos, nesses esforços. A multipolaridade, baseada em normas multilateralmente aceitas, oferece as condições mais propícias a que o Brasil defina com autonomia os seus interesses e leve a efeito uma grande estratégia que inclua não apenas a dimensão de um país pacífico, mas um país provedor de paz.

Atravessamos um período de transição entre a mentalidade unipolar, o risco de nova bipolaridade e a promessa da multipolaridade. É contra esse pano de fundo que se devem examinar as áreas dinâmicas de algumas das situações com potencial de conflito na realidade atual. Uma dessas situações refere-se às disputas sobre territórios marítimos ricos em recursos naturais na Ásia, em que diferentes Estados pleiteiam a extensão de suas jurisdições sobre espaços que se superpõem. Temos assistido a uma competição que envolve potências regionais, como a China, o Japão, a Coréia do Sul, as Filipinas,

6 Na iminência da II Guerra do Golfo, os defensores de um ataque militar utilizaram abundantemente a ideia, prenhe de implicações perigosas, de preemptive self-defense. 
o Vietnã e a Índia, além de potências extrarregionais, como os Estados Unidos. A evolução recente nessa área indica, em primeiro lugar, um esforço do Governo norte-americano em reorientar seu engajamento político-militar, no chamado "pivô para a Ásia".

Em editorial, importante jornal dos Estados Unidos apoiou as medidas do governo japonês na direção de maior flexibilidade no emprego de sua força militar e cobrou a formação de uma aliança de democracias na Ásia para contrabalançar - são palavras do editorial - a ascensão chinesa. A insuficiência na Ásia de mecanismos de criação de confiança, promoção de transparência e definição de regras comuns de conduta é um fato ponderável na análise da evolução daquela região.

Outra área, que é palco de grandes mudanças - nem todas de sentido positivo - é o Oriente Médio. A chamada "primavera árabe" despertou grandes esperanças de que vários países caminhassem para ordenamentos políticos mais democráticos, com maior participação popular. Mas com a possível exceção da Tunísia (e mesmo ela sujeita a violentas erupções terroristas que põem em xeque a capacidade do governo de enfrentar a atração de doutrinas fundamentalistas), o que se viu foi a degeneração do movimento democrático em conflitos faccionais, como na Síria, ou o retrocesso puro e simples em direção ao autoritarismo, como no Egito.

Despontaram, nos últimos anos, inquietações acerca do futuro do status quo territorial criado pelo famoso Acordo Sykes-Picot, entre a França e a Grã Bretanha, prevendo o fim do Império Otomano ao final da Primeira Guerra. Isso até poderia ser positivo, caso o encaminhamento das mudanças tivesse ocorrido de forma pacífica - o que é obviamente não é o caso. A famosa expressão de Marx de que a "violência é a parteira da História" aplica-se plenamente ao Oriente Médio, só que não em direção do progresso social e político, como preconizava o pensador alemão.

A possibilidade de que o mapa do Oriente Médio, tal como foi desenhado há aproximadamente um século, deixe de existir é vista mais com apreensão do que com esperança. Algumas das ações das grandes potências contribuíram fortemente para essa evolução. O apoio político e a concessão de armamentos a facções revoltosas alimentaram setores fundamentalistas, do mesmo modo que, no outro extremo, a ajuda militar a governos autoritários não estimulou a busca de soluções pelo diálogo.

Do outro lado da balança, o recente acordo entre os $\mathrm{P}_{5}+\mathrm{I}$ e o Irã cria uma expectativa positiva para o encaminhamento de certas questões como o futuro do Iraque e da Síria (e a correlata questão do autodenominado "estado islâmico"), não obstante os temores, por razões distintas, de alguns países da região como a Arábia Saudita e Israel. 
No Oriente Médio, fatores de ordem estratégica mesclam-se com interesses por acesso a recursos naturais e acentuam clivagens étnicas ou religiosas. Até há pouco, a Síria vinha sendo um microcosmo dessas tensões. Hoje, ela disputa essa posição com o Iraque, sem falar no Iêmen. $\mathrm{O}$ acordo patrocinado pela Rússia e apoiado pelos Estados Unidos em setembro de 20I3, que prevê a destruição do arsenal químico sírio, foi um sinal encorajador do espaço aberto à diplomacia. Pouca gente sabe, mas o enviado especial do Diretor da Organização de Proibição de Armas Químicas nessa importante missão, é um brasileiro, o Embaixador José Artur Denot Medeiros, que durante cinco anos foi nosso representante junto à OPAQ.

É comum ouvir-se, no caso da Síria, o conhecido (e correto) refrão de que não há solução militar para o conflito. Ao mesmo tempo, o comportamento das grandes potências, armando um ou outro lado da guerra civil, contrasta com essa propalada convicção pacifista. A desestabilização causada na Líbia e no Norte da África pela intervenção militar anglo-franco-americana contra o regime Gaddafi, em 20II, se insere no mesmo cenário.

Ao drama dos refugiados se soma o dos imigrantes. Embora a interferência externa no conflito sírio não tenha alcançado proporções similares, é preciso registrar que a conflagração naquele país já transbordou para países vizinhos, como ficou claro no atentado em Beirute que vitimou nossa compatriota Malak Zahwe.

A ameaça de um "estado islâmico" agressivo se estende do Oriente Médio até praticamente o Golfo da Guiné. Crises como a da Síria exigem uma postura de respeito às regras da $\mathrm{ONU}$ e de trabalho conjunto com todas as partes interessadas que possam ter influência sobre o processo político em curso, inclusive - no caso - o Irã. O que quero indicar é que, ao contrário do que muitas vezes vemos ser defendido, a intervenção estrangeira é um remédio que costuma atacar o paciente, e não a doença. A situação do Iraque pós2003, ameaçado por conflitos étnico-religiosos e pela proliferação de grupos terroristas tem sido uma triste demonstração disso.

Uma situação que evidencia a fluidez crescente na realidade internacional contemporânea é constituída pelos vastos espaços localizados fora da jurisdição nacional dos Estados soberanos ou nos seus limites, caso das profundezas oceânicas, das altas latitudes e do espaço sideral. Essas áreas não estão livres de pretensões de controle hegemônico (e não falo aqui de uma única superpotência) em detrimento de direitos de Estados costeiros ou da exploração segundo regras multilaterais de conduta. A abertura de novas rotas e as possibilidades de exploração no Ártico deram ímpeto à discussão do assunto. Um editorial do Financial Times observou, sobre aquela região, que, "por enquanto, a contenda por recursos permanece polida. Mas isso pode não 
durar, se as descobertas passarem à frente das regras do jogo". Obviamente, esse risco não se limita ao Ártico. Ele se estende a todos os pontos do planeta em que a disputa por recursos naturais tenderá a acirrar-se, à medida que cresce a demanda mundial. O Atlântico Sul, área do nosso interesse direito, não estará livre dele.

O espaço cibernético é outra dimensão em que é visível o engajamento com fins econômicos e militares por parte das grandes potências. Por estar ainda em seus princípios, a guerra cibernética ainda não é um fenômeno plenamente conhecido. Indaga-se já, porém, em analogia com as concepções vigentes à época da Primeira Guerra Mundial, se não se está criando um "culto da ofensiva cibernética". Essa impressão é reforçada por iniciativas como a decisão tomada por um importante país, a Grã Bretanha, no sentido de desenvolver capacidades de ataque (e não apenas de defesa) no campo cibernético. A abordagem franca do tema pelo Ministro do país em questão causou grande repercussão. Mas certamente Londres não é a única capital a perseguir essa via. O caso do vírus Stuxnet, que atacou o programa nuclear do Irã, deve ser estudado com cuidado, ainda mais quando se conhece a tendência, em certos círculos, de estender o conceito e o alcance da não-proliferação para o de "contra-proliferação".

Segundo alguns especialistas, novas tecnologias de guerra como a cibernética, mas também os veículos aéreos não tripulados, apagarão as distinções tradicionais entre "guerra" e "paz", "militar" e "civil", "estrangeiro" e "doméstico" e "nacional" e "internacional", com o potencial de inverter a lógica da aversão ao risco a que me referi antes. Mais amplamente, o que vai surgindo no horizonte é a possibilidade de que se instaure um estado de beligerância permanente entre países adversários, até porque as fronteiras entre a espionagem e a guerra não são definidas com precisão. Para David Rothkopf, editor da revista Foreign Policy, trata-se de um novo tipo de guerra, que chama em inglês de Cool War, por oposição à Cold War. Ao passo que na Guerra Fria a destruição mútua assegurada (significativamente conhecida como "MAD", na sigla em inglês) pelas armas nucleares evitava que as superpotências se atacassem, nessa nova guerra, um pouco mais 'quente' que a anterior, cada contendor poderia ser capaz de "atacar constantemente, sem desencadear uma guerra aberta”. Países como o Brasil não podem ficar indiferentes aos sinais de que essas linhas de pensamento venham a prevalecer.

O denominador comum das tensões territoriais na Ásia, dos riscos de fragmentação no Oriente Médio, da rivalidade nos fundos marinhos e da militarização do espaço cibernético, entre várias outras áreas fluidas do sistema internacional, é o potencial de se alastrarem globalmente, inevitavelmente afetando o Brasil e o nosso entorno, a começar pela América do Sul e o Atlân- 
tico Sul, no processo. Alguns desses elementos de tensão estão, naturalmente, mais distantes de nós, enquanto outros inspiram cuidados mais imediatos. Todos têm, contudo, repercussão sistêmica, e podem ser fatores de vulnerabilidade para os interesses brasileiros e de outros países sul-americanos, que nos interessa coletivamente proteger.

Um razoável equilíbrio do poder mundial é condição fundamental, ainda que não suficiente, para a manutenção da paz. Esse é um dos pressupostos da grande estratégia do Brasil, que combina poder brando e poder robusto na busca de prover a paz. Cumpre-nos estar adequadamente capacitados para defender nosso território, nossa população e nossos interesses. O objetivo dessas e de muitas outras medidas é garantir ao Brasil a posse, com domínio tecnológico, de meios que afastem ameaças e agressões que possamos vir a sofrer a qualquer tempo e originadas em qualquer quadrante.

Para defender, não basta dissuadir. É preciso também cooperar. Esse tem sido e deve continuar a ser o princípio básico da política de defesa no entorno estratégico brasileiro. Com os vizinhos da América do Sul, vamos aprofundando a confiança, a transparência e a visão comum dos objetivos de Defesa, bilateralmente e por meio do Conselho Sul-Americano de Defesa. A defesa da América do Sul é uma responsabilidade dos sul-americanos. É importante que, progressivamente, essa visão impregne as políticas de todos os países do nosso subcontinente. A recém-criada Escola Sul-Americana de Defesa (ESUDE), com sede em Quito, mas que atuará de forma decentralizada, é um grande passo para aprofundar e estender a cooperação tradicional que já temos com outras nações sul-americanas. Devemos levar essa cooperação a novas áreas, como as da indústria e da alta tecnologia, como a aeroespacial e a cibernética (o que já começa a ocorrer) bem como a países que, em virtude de seu desenvolvimento ainda incipiente, sejam mais vulneráveis a incursões de interesses extrarregionais.

Também no Atlântico Sul, são dignas de nota a cooperação que temos prestado à formação da guarda costeira e à capacidade naval de Cabo Verde e a assessoria que a Marinha está dando à União Africana, no que diz respeito à segurança marítima. A Marinha brasileira, de forma pioneira, estendeu a cooperação com a Namíbia e se tem feito presente nas discussões e exercícios relativos à segurança no Golfo da Guiné. E não é apenas por solidariedade, que também é relevante, mas por interesse direto do Brasil, porque por lá passa boa parte do nosso comércio com a África, principalmente do nosso suprimento de petróleo. Por meio da ZOPACAS7, unimos esforços para que nosso oceano seja uma zona de paz e cooperação, livre de armas nucleares e

7 A Zona de Paz e Cooperação do Atlântico Sul (ZOPACAS) foi estabelecida em I986, por meio da Resolução 4I/II da Assembleia Geral das Nações Unidas. 
de todo tipo de rivalidades estranhas ao nosso entorno.

O entendimento realista das necessidades de defesa do Brasil no mundo tem precursores insignes. Foi com grande presciência que Rui Barbosa, em obra de i896, ponderou que "a paz é a cláusula essencial do nosso progresso. Mas (...) a primeira condição da paz é a respeitabilidade, e a da respeitabilidade a força”. Ou, em terminologia mais atual: o poder brando deve estar apoiado no poder robusto.

\section{REFERÊNCIAS}

Amorim, Celso. 2015. Teerã, Ramalá e Doha: memórias da política externa ativa e altiva. São Paulo: Benvirá.

Nye, Joseph. 2004. Soft Power: The Means to Success in World Politics. New York: Public Affairs Press.

Zakaria, Fareed. 2009. The post-American world and the rise of the rest. London: The Penguin Books.

New York Times. 2015. Four Ideas for a Stronger U.N. February 6, 2015. http:// www.nytimes.com/2015/02/07/opinion/kofi-annan-gro-harlembruntland-four-ideas-for-a-stronger-un.html?_r=o

\section{RESUMO}

Nos últimos anos do século XX, com o fim da Guerra Fria, o mundo evoluiu para uma estrutura mista, que conserva traços da unipolaridade, mas que, em certos aspectos, se aproxima de um mundo multipolar. Em uma realidade internacional de natureza fluida, a emergência de novos atores e das chamadas "ameaças assimétricas" não eliminou os antigos agentes na ordem mundial, e o conflito entre Estados não desapareceu de todo do horizonte. Nessa conjuntura, a diplomacia deve ter o respaldo permanente da política de defesa. Para tanto, no caso brasileiro, o artigo apresenta que o país deve adotar uma grande estratégia que conjugue política externa e política de defesa, na qual o poder brando (soft power) será reforçado pelo poder robusto (hard power).

\section{PALAVRAS-CHAVE}

Grande Estratégia; Política Externa; Política de Defesa; Brasil.

Recebido em 11 de agosto de 2015. Aprovado em 2 de setembro de 2015. 